\title{
JESZCZE RAZ O FUNKCJI AOJDY NA DWORZE AGAMEMNONA (ODYSEJA III 263-272)
}

Georgio amico optimo

W roku 1981 Stephen P. Scully przedstawił szczegółowo interpretację roli aojdy w homeryckim społeczeństwie, przy czym zainteresował się przede wszystkim rolą bezimiennego śpiewaka, któremu Agamemnon powierzył przed wyjazdem pod Troję troskę o swoja żonę Klitajmestrę ${ }^{1}$. Dowodził jego wyjątkowej w społeczeństwie Homerowym, wychowawczej roli². Przytoczona argumentacja była przekonywająca, zgodna w ogólnych wnioskach z tradycyjną w literaturze naukowej wykładnią․

Kiedy zachęcony przez profesor Marię Korytowską pochyliłem się nad tematem natchnienia poetyckiego, a ściślej nad Mnemosyne i jej córkami w greckiej kulturze, z konieczności podjąłem i kwestię paideutycznej roli aojdów w społeczeństwie homeryckim. $Z$ całym przekonaniem dowodziłem słuchaczom $^{4}$, że potrzeba polityczna i społeczny szacunek zadecydował o stałej ich obecności na dworach królewskich. Opierając się na wcześniejszych moich analizach, opowiadałem ${ }^{5}$, że obraz pieśniarza Demodoka na dworze Alkinoosa z VIII księgi Odysei dowodnie oddaje nadzwyczajny autorytet aojdy. Zgodziłem się z badaczami cywilizacji greckiej uważającymi, że epoka archaiczna to kultura oparta na wzorcach postępowania i działania, które to wzorce przypominali w swoich pieśniach aojdowie wędrujący od pałacu do

${ }^{*}$ Prof. dr hab. Kazimierz Korus - emerytowany profesor zwyczajny Uniwersytetu Jagiellońskiego; e-mail: kkorus@poczta.onet.pl.

${ }^{1}$ Por. Homerus, Odyssea III 263-272.

${ }^{2}$ Por. S.P. Scully, The Bard as the Custodian of Homeric Society: „Odyssey” 3, 263-272, „Quaderni Urbinati di Cultura Classica. New Series” 8 (1981) 78: „The singer/poet does not have the strength of the king, or of anyone else in his society, but because he is transmitter, teacher and constructor of the values in that society, he can serve, this passage suggests, as surrogate king".

${ }^{3}$ Por. np. J. Latacz, Aoiden, w: Der neue Pauly. Enzyklopädie der Antike, Stuttgart - Weimar 1996, 620-621, tam literatura przedmiotu do 1991 r.; G.M.A. Grube, The Greek and Roman Critics, London 1965, 2-9.

${ }^{4}$ Podczas konferencji, która miała miejsce w Krakowie, w dniach 4-6 listopada 2015 r., wygłosiłem odczyt pt. Mnemosyne w greckiej polityce i kulturze.

${ }^{5}$ Por. K. Korus, Mim grecki w gatunkach literackich, Prace Komisji Filologii Klasycznej PAU 47, Kraków 2015, 45-56. 
pałacu, występujący podczas świąt religijnych i świąt miast-państw (polisowych) $w$ agonach poetyckich. $Z$ jednej strony chronili oni prawo obyczajowe, a $\mathrm{z}$ drugiej, przywołując dawne wzorce postępowania, ułatwiali władcom rozstrzyganie sporów, uśmierzali gniewy, obrazami przeszłości rozstrzygali, co sprawiedliwe, słuszne i godne szlachetnych ludzi ${ }^{6}$. Mówiłem też, że o tym, jak wielkim autorytetem cieszyli się śpiewacy na dworach królewskich, świadczy zachowanie Klitajmestry, która planując podczas nieobecności męża wyjście za mąż za Ajgistosa, dobrze zdawała sobie sprawę z niegodziwości czynu tak z punktu widzenia moralnego, jak i politycznego. Ślubem przecież przekazywała władzę obcemu. Na dworze miała jednak aojdę czuwającego nad moralnością mieszkańców, a szczególnie jej, jako żony króla. Tak jak wtedy przytaczałem, tak i tu przypomnę cały kontekst. Homer ustami Nestora przedstawia bardzo wyraziście całą dramatyczną sytuację. Najpierw próbuje królową bronić, a potem tak oskarża: [Ajgistos] spokojnie sobie uwodził Agamemnonową żonę. $\mathrm{Z}$ początku wzbraniała się przed sromotą [dosłownie: czynem niegodnym, nieprzystojnym] boska Klitajmestra, bo duszę miała zacna, a był przy niej i pieśniarz, któremu Atryda idąc na Troję usilnie zlecił czuwać nad żoną. Ale gdy wola boża zmusiła ją ulec, wtedy tego aojda wysłała na wyspę bezludną i zostawiła ptakom na łup i żer ${ }^{8}$.

W dziejach recepcji mitu o domu Atrydów dla mnie ów aojda pozostał bezimiennym symbolem prawości, chroniącym wysokie normy prawa obyczajowego, który swą służbę przypłacił życiem. Zdawało mi się, że po artykule, wyżej wspomnianego Stephena P. Scully’ego właściwie tylko przypomniałem w ten sposób słuchaczom obowiązującą w nauce interpretację tego passusu. Już po wykładzie, na wszelki jednak wypadek zaglądnąłem do znakomitego, trzytomowego wydania komentarza do Odysei. Otóż okazało się, że w kilka lat później po artykule Scully'ego, komentatorka pierwszych ośmiu ksiagg, profesor Stephanie West (Oxford), przedstawiła wstępnie argumenty za zupełnie inną interpretacją i zachęciła czytelników do dalszej dyskusji nad szczególną rolą aojdy na dworze Agamemnona9. Postanowiłem podjąć dyskusję i obronić nie tylko S.P. Scully'ego, ale i moje stanowisko.

\footnotetext{
${ }^{6}$ Por. W. Jaeger, Paideia, tłum. M. Plezia, Warszawa 1962, 53: „doniosłość takiego wzoru dla rozwoju pewnego typu kultury Grecy odczuwali zawsze wyraźnie, zresztą w kształtowaniu się każdej kultury szlacheckiej odgrywa on rolę decydującą". Por. też ogólne wprowadzenie do roli aojdy w epoce homeryckiej E. Mireaux, Życie codzienne w Grecji w epoce homeryckiej, thum. S. Kołodziejczyk, Warszawa 1962, spec. rozdział pt. Aojdowie i przewodnicy chórów, s. 74-80.

${ }^{7}$ Por. Homerus, Odyssea III 253-328.

${ }^{8}$ Por. tamże III 263-272; tłum. J. Parandowski: Homer, Odyseja, Warszawa 1953, 38.

${ }^{9} \mathrm{~S}$. West w komentarzu do Odysei (A. Heubeck - S. West - J.B. Hainsworth, A Commentary on Homer's Odyssey, vol I. Introduction and Books I-VIII, Oxford 1990) wskazuje (s. 177) na prace D.L. Page'a, The Mystery of the Minstrel at the Court of Agamemnon, wydrukowana przed ponad pięćdziesięciu laty w: Studi classici in onore di Quintino Cataudella, Università di Catania 1972, 127-130, jako inspirującą do dyskusji.
} 
Jakie są argumenty prof. S. West? W przypisie podaję je $\mathrm{w}$ całości ${ }^{10}$, a tu zestawiam w pewnym porządku, aby z nimi polemizować. Prof. S. West pisze:

a. Aojda jako strażnik, obrońca królowej tu (na dworze Agamemnona) byłby postacią wyjątkowa, bo nie spotykamy go w tej roli na innych dworach.

b. Scholiaści, starożytni komentatorzy, byli wyraźnie zakłopotani, jak interpretować jego funkcję na dworze.

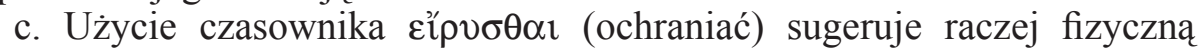
ochronę.

d. Atenajos w Uczcie mędrców (14 b) nie ma racji, mówiąc, że zadaniem aojdy było pilnować Klitajmestry $i$ stużyć jej rada, ponieważ rapsodzi ${ }^{11}$ w Odysei nie służyli radą ani zachętą. Jego interpretacja sugeruje bardziej Hezjodową wizję poezji.

S. West uznaje za warte rozważenia alternatywne wyjaśnienie. Wprawdzie zostało ono odrzucone w scholiach, ale wyraźnie zasugerowane w Leksykonie

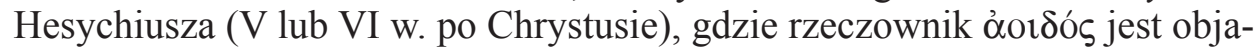
śniany terminem $\varepsilon \hat{v} v o \hat{\chi} \chi \varsigma \varsigma, \sigma \pi \alpha ́ \delta \omega v^{12}$. Eunuch jako obrońca królowej byłby zdaniem Autorki bardziej do przyjęcia w interpretacji tego passusu, chociaż w Iliadzie mówi się o kastrowaniu zwierząt ${ }^{13}$, nie ma natomiast wzmianki

${ }^{10}$ Por. A. Heubeck - S. West - J.B. Hainsworth, A Commentary on Homer's Odyssey, vol. 1, s. 176: „The minstrel as the queen's guardian is another curiosity of which there is no trace in any other authority. The ancient commentators were clearly puzzled, but inclined to the view that the minstrel was supposed to recount stories of womanly excellence, and thus inspire Clytaemestra to emulation while diverting her mind from improper thoughts; cf. Athen. $14 \mathrm{~b}$. This implies a more Hesiodic style of poetry; the minstrels of the Odyssey do not offer advice or exhortation. But eirysthai (268) rather suggests physical protection, though a bard sufficiently able-bodied to be an effective guardian might himself be tempted to rape or seduction. It is worth considering an alternative explanation [podkreślenie K.K.], rejected in the scholia but perhaps reflected (or corroborated?) in Hesychius' Lexicon, where aoidós is glossed with ho eunoúchos, spádon. Certainly castration in boyhood would account for this odd combination of duties; but though the castration of animals was evidently familiar (cf. Il. XXIII 147 énorcha méla), Greek literature does not refer to the castration of men before the fifth century, when it was evidently regarded as a barbarous Oriental practice (A. Eu. 187 ff., Hdt. III 48.2, VIII 105-6). Still, there are few literary references to the castrati who played an important part in opera from the seventeenth to the late nineteenth century, and the argument from silence may not be a conclusive objection in this case".

${ }^{11}$ Czasem wymiennie, ze względów stylistycznych, używamy w literaturze słów aojda i rapsod, ale przecież towarzyszy nam świadomość pewnego anachronizmu. Rzeczownik rapsod pojawia się w literaturze greckiej dopiero w V w. przed Chrystusem. Wśród tych zawodowych pieśniarzy powszechnie jest znany rapsod, z którym w Ionie Platona rozmawia Sokrates. Por. słuszne uwagi

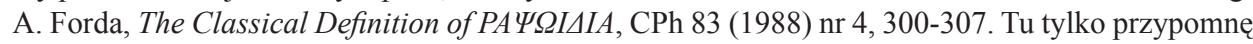
jego najistotniejsze stwierdzenie (s. 300): „The earliest history of these words is obscure. We first find rhapsodós in the fifth century (GDI 5786 [Dodona], Soph. OT 391), but the name and practice may be older: there are evident paraphrases of the term in pseudo-Hesiod and Pindar (frag. 357 M.-W.; Isthm. 3 [4]. 56-57, Nem. 2. 2), and Herodotus (5. 67) refers to rhapsodes active in sixth-century Sicyon".

${ }^{12}$ Hesychius Alexandrinus, Lexicon A 5662-5663, rec. K. Latte, t. 1, Hauniae 1953, 194.

${ }^{13}$ Por. Homerus, Ilias XXIII 147. 
o eunuchach. Ajschylos ${ }^{14}$ oraz Herodot ${ }^{15}$ jednak wyraźnie o nich wspominają jako o orientalnym barbarzyństwie.

Najpierw z naciskiem trzeba zaznaczyć, że powyższe argumenty nie przesądzaja, tylko sugerują inny, odmienny od dotychczasowego sposób interpretowania fragmentu. Dlatego proponuję rozważenie każdego z nich.

Ad a. Trafne jest spostrzeżenie, że nie znamy w epoce homeryckiej dworu królewskiego, w którym pieśniarzowi powierzone by było zadanie strzeżenia królowej. Trzeba jednak odpowiedzieć na pytanie, dlaczego dom Agamemnona stanowił wyjątek. Homer przedstawia właściwie tylko trzy dwory królewskie, na których odgrywał znaczącą rolę aojda: pałace Odysa, Alkinoosa i Agamemnona. W pierwszych dwóch małżeństwo opiera się na mądrości i wierności kobiet Penelopy i Arety. W jedenastej księdze poeta, przedstawiając zejście Odysa do świata zmarłych, wkłada w usta Agamemnona, zamordowanego przez Ajgista, porównanie Klitajmestry i Penelopy ${ }^{16}$. Pierwsza otrzymuje wyłącznie cechy negatywne, wypływające ze zdradliwego serca. Agamemnon nazywa ją podobnie do Ajgista ,zdradliwą" $(\delta o \lambda o ́ \mu \eta \tau \iota \varsigma)^{17}$, a potem, opisując, jak mordowała Kasandrę, woła pod wpływem emocji: „nie masz nic bardziej szkaradnego i psiego nad kobiete" ${ }^{18}$. Natomiast Penelopa według niego jest jej przeciwieństwem. Obdarza ją przymiotnikiem „mądra” (per...frwn), a ,jej rozum jest pełen dobrych rad" ${ }^{19}$. Agamemnon również odpowiada na pytanie, dlaczego zlecił aojdzie czuwanie nad żoną: „Zaprawdę wierzyłem, że z miłością powitają mnie w domu dzieci i czeladź" ${ }^{20}$. Tu warto zwrócić uwagę na czasownik grecki œfhn, dobrze przełożony przez Jana Parandowskiego „wierzyłem”. Dosłownie oznacza on: „mówiłem do swojej duszy, do siebie”, a stąd tłumaczyć możemy: ,powtarzałem sobie, myślałem, wierzyłem, tak sobie wyobrażałem" itp.

Aojda zatem miał przez swoje pieśni odwoływać się do duszy, wyobraźni i serca Klitajmestry i budować jej pozytywny stosunek do męża.

Jeżeli przyjmiemy powyższe rozumowanie, to teraz już wiemy, dlaczego nigdzie nie spotykamy aojdy z zadaniem strzeżenia królowej. Po prostu dlatego, że małżeństwo Agamemnona stanowiło wyjątek na tle normalnych królewskich małżeństw Odysa i Penelopy czy Alkinoosa i Arety. Było przez bogów przeklęte, jak cały ród Atrydów, po uczcie Tyestesa, któremu brat Atreus podał ciała jego dzieci jako potrawę. Władzę, której symbolem było berło, po Tyestesie odziedziczył właśnie na swoją zgubę Agamemnon ${ }^{21}$.

${ }^{14}$ Por. Aeschylus, Eumenides 187.

${ }^{15}$ Por. Herodotus, Historiae III 48, 2; tamże VIII 105-106.

${ }^{16}$ Por. Homerus, Odyssea XI 405-464.

${ }^{17}$ Tamże XI 422, ed. A.T. Murray: Homer, Odyssey, t. 1, LCL 104, Cambridge (Mass.) - London 1960, 416.

18 Tamże XI 427, LCL 104, 416, thum. Parandowski, s. 165.

${ }^{19}$ Tamże XI 446, LCL 104, 416, thum. Parandowski, s. 166.

${ }^{20}$ Tamże XI 430, LCL 104, 416, thum. Parandowski, s. 166.

${ }^{21}$ Por. tenże, Ilias II 101-109. 
Ad b. Zajmijmy się teraz kwestią zakłopotania komentatorów (,The ancient commentators were clearly puzzled"). Scholiaści, komentując słowa po-

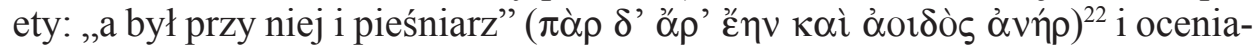
jąc pozycję aojdy na dworze Klitajmestry, wyraźnie opowiadają się za rozumieniem jego wychowawczej (paideutycznej) funkcji. Czytamy tam najpierw stwierdzenie uogólniające, że starożytni cenili aojdów jako ludzi mądrych, podobnie jak filozofów, potem zaś zdecydowane wyjaśnienie: „pieśniarz [tu pojawia się druga nazwa aojdy: $\grave{\delta} \delta$ śs] powstrzymywał Klitajmestrę od ha-

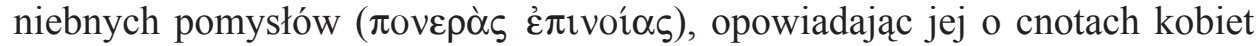
i mężczyzn"23. I na końcu scholiasta zaznacza, że dopóki był przy niej, zachowała rozsądek. Inny nieznany komentator, w tym samym miejscu zacytowany, zgadza się z tą interpretacją i zdecydowanie odrzuca inne opinie, które błędnie

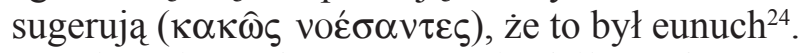

Słusznie prof. S. West stwierdziła, że komentatorzy są skłonni do przyjęcia paideutycznej roli aojdy. Równocześnie odrzuciła stanowisko komentatora Atenajosa (żył w II w. po Chr.), który w Uczcie mędrców tak podsumował dotychczasowe komentarze: „Ród śpiewaków cechowała pewna roztropność, a ich znaczenie było takie jak filozofów. Agamemnon na przykład pozostawia śpiewaka, by pilnował Klitajmestry i służył jej radą. Poprzez opowieści o kobiecych zaletach przede wszystkim zaszczepiał w niej pragnienie dążenia do tego, co piękne i dobre, a słodko umilając jej czas - odwracał też myśli od niecnych zamiarów"25.

Zestawiając słowa scholiastów i Atenajosa, stwierdzamy ich jednomyślność w ocenie roli aojdy ${ }^{26}$. Nie można się zgodzić z sugestią S. West, że Atenajosa wizja aojdy jako nauczyciela i autorytetu w zakresie moralności na dworach królewskich jest wizją Hezjodową. Ten sam Atenajos przecież uzasadnia swoje stanowisko nieco dalej ${ }^{27}$ przykładami z Odysei, a nie z utworów Hezjoda. Wymienia Femiosa piętnującego zalotników i w ten sposób wspierającego Penelopę, także wskazuje na wychowawczą rolę Demodoka. Nakaz

${ }^{22}$ Tenże, Odyssea III 267, LCL 104, 86, tłum. Parandowski, s. 38.

${ }^{23}$ Scholia Graeca in Homeri Odysseam, ed. G. Dindorf, t. 1, Oxonii 1855, 148 (E.M.) - komentarz nieznanego scholiasty do księgi III w. 267), tłum. własne.

${ }^{24}$ Por. tamże (M.Q.V.).

${ }^{25}$ Athenaeus, Deipnosophistae I 14 b, ed. C.B. Gulick: Athenaeus, The Learned Banqueters, t. 1, LCL 204, London 1961, 60, tłum. K. Bartol - J. Danilewicz: Atenajos, Uczta mędrców, Poznań 2010, 96-97.

${ }^{26}$ Por. K. Bartol, The Voice of Tradition: Representations of Homeric Singers in Athenaeus 1.14a-d, CQ N.S. 57 (2007) nr 1, 231-243. Por. zwłaszcza bogatą w przypisy ogólną uwagę Autorki (s. 234): „The thought that in the Homeric world it was the singer who had moral supervision of the ruler and members of a community, and who guarded its time-honoured social order must have been deeply ingrained in the Greeks' minds, since the story of Agamemnon's minstrel was a subject of comments made by ancient scholars, and Demetrius of Phalerum seems even to regard the unnamed Homeric aoidos and Demodocus, the famous bard of the Phaeacians, as being identical".

${ }^{27}$ Por. Athenaeus, Deipnosophistae I $14 \mathrm{c}$. 
pilnowania dotyczył nie fizycznej możliwości aojdy (eunucha?!) przeciwstawienia się Ajgistowi, a wyłącznie moralnej, związanej z jego autorytetem społecznym. Ponieważ był natchniony przez Muzy, dbał o prawdę w przekazie sławnych czynów bohaterów i oparte na niej prawo obyczajowe.

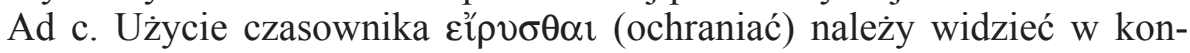
tekście językowego zastosowania w tekstach Homerowych i w kontekstach zbliżonych. Jeżeli zaglądniemy do naukowych słowników, to przeczytamy, że czasownik ten ma dwa znaczenia: realne oraz metaforyczne. Realne odnosi się do fizycznego pilnowania czegoś, np. okrętów ${ }^{28}$, a metaforyczne skierowane jest też na pilnowanie, ale siebie samego, ustrzeżenie siebie lub innych przed czymś, zachowywania czegoś w sercu swoim, np. tajemnicy ${ }^{29}$ lub praw obyczajowych, boskich ${ }^{30}$ itp. Warto tu przytoczyć w całości kontekst podobnego metaforycznego zastosowania czasownika eipúo $\mu \alpha \imath$ właśnie w Odysei $i^{31}$, ponieważ jego znaczenie jest bliskie tu omawianemu passusowi, odnosi się do podobnej sytuacji. Rzecz się dzieje na dworze Penelopy już po zabójstwie zalotników. Odys radzi Telemachowi, aby dla ostrożności i niewywoływania paniki w mieście przygotować się do hucznej zabawy i stworzyć wrażenie, że Penelopa wyprawia wesele. W tym kontekście, jak powiada wszechwiedzący narrator, ktoś, kto usłyszy muzykę i tańce na dworze Penelopy, może sobie pomyśleć, że rzeczywiście królowa wychodzi za mąż i powie:

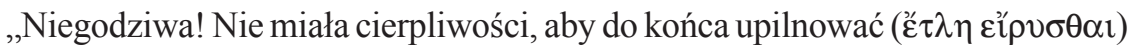

wielkiego domu prawnie poślubionego małżonka, dopóki ten nie powróci”32.

Metafora jest oczywista. W fikcyjnej sytuacji stworzonej przez Odysa w ocenie domniemanego przechodnia ( $\tau \iota \varsigma$ عí $\pi \varepsilon \sigma \kappa \varepsilon$ ) Penelopie zabrakło cierpliwości, aby uchronić się przed zdradą. Wychodząc za mąż, nie upilnowała domu ,prawowitego małżonka”. Nie chodzi tu więc o fizyczne pilnowanie domu, ale moralne.

Moim zdaniem bardzo podobna jest konsytuacja w przypadku opisu zachowania królowej na dworze Agamemnona, który aojdzie polecił pilnować Klitajmestrę, aby pomóc jej ustrzec się przed zdradą, swoimi pieśniami, swoim autorytetem, mądrością, jak to thumaczy Atenajos, a nie siłą fizyczną, jak to zdaje się sugerować S. West, autorka komentarza.

Ad d. Gdy do tego dodamy, że w epoce Homerowej nie ma wzmianki o jakimkolwiek rapsodzie eunuchu, o czym zgodnie z prawdą informuje S. West, to interpretację Hezychiusza (aojda = eunuch) trzeba nam odnieść wyłącznie do czasów późniejszych.

\footnotetext{
${ }^{28}$ Por. Homerus, Odyssea XIV 259.

${ }^{29}$ Por. tamże XVI 459.

${ }^{30}$ Por. tenże, Ilias I 239.

${ }^{31}$ Por. tenże, Odyssea XXIII 140-151.

${ }^{32}$ Tamże XXIII 150-151, LCL 105, 384, thum. Parandowski, s. 334.
} 
W podsumowaniu moich rozważań wypada mi zaznaczyć, że w zaproponowanej przez prof. S. West dyskusji skłonny jestem opowiedzieć się po stronie obrońców paideutycznej roli aojdy na dworze Klitajmestry. Zginął jako obrońca dobrego obyczaju.

Agamemnon zostawił go na swoim dworze ze względu na jego wśród dworzan i ludu wielki autorytet, jako głosiciela prawdy o szlachetnych obyczajach i czynach przodków. Miał w swych pieśniach, jak Femios na dworze Penelopy, głosić sławę cnót mądrych i wiernych kobiet i w ten sposób strzec królową przed popełnieniem niegodziwego czynu.

\section{ONCE AGAIN ABOUT THE FUNCTION OF THE BARD AT THE COURT OF THE KING AGAMEMNON (ODYSSEA III 263-272)}

\section{(Summary)}

This paper looks at two accounts of scholars' views on the bard as the custodian of Homeric Society (Odyssea III 263-272). The first traditional, defended by Stephen P. Scully, sees a singer, an unnamed singer, as a moral guard of Clytaemnestra. The second, defended by Stephanie West, suggests that it is worth an alternative explanation, rejected in the scholia but perhaps reflected (or corroborated?)

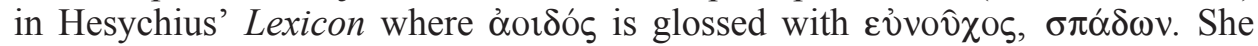
says that the word eipvi $\sigma \theta \alpha$ (Odyssea III 268) suggests rather physical protection though a bard sufficiently able-bodied is an effective guardian might himself be tempted to rape or seduction.

The Author of the article defends traditional understanding of the role of bard with many other arguments. He is convinced that the singer was removed from the palace because his presence reminded Aegisthus and Clytaemnestra of their wrong to society.

Key words: function of the bard, Agamemnon, Aegisthus, Clytaemnestra.

Słowa kluczowe: funkcja aojdy, Agamemnon, Ajgistos, Klitajmestra.

\section{BIBLIOGRAFIA}

\section{Źródła}

Athenaeus, Deipnosophistae, ed. C.B. Gulick: Athenaeus, The Learned Banqueters, t. 1-7, LCL 204 (I-III), LCL 208 (III-V), LCL 224 (VI-VII), LCL 235 (VIII-X), LCL 274 (X-XI), LCL 327 (XII-XIII), LCL 345 (XIII-XIV), London 1955-1961, thum.

K. Bartol - J. Danilewicz: Atenajos, Uczta mędrców, Poznań 2010.

Homerus, Odyssea, ed. A.T. Murray: Homer, Odyssey, t. 1-2, LCL 104-105, Cambridge

(Mass.) - London 1960, thum. J. Parandowski: Homer, Odyseja, Warszawa 1953.

Homerus, Ilias, ed. A.T. Murray: Homer, Iliad, t. 1-2, LCL 170-171, London 1924-1925. Hesychius Alexandrinus, Lexicon, rec. K. Latte, t. 1-2, Hauniae 1953-1966.

Scholia Graeca in Homeri Odysseam, ed. G. Dindorf, t. 1-2, Oxonii 1855. 
Opracowania

BARtol K., The Voice of Tradition: Representations of Homeric Singers in Athenaeus 1.14a-d, CQ N.S. 57 (2007) nr 1, 231-243.

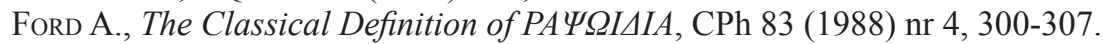

Grube G.M.A., The Greek and Roman Critics, London 1965.

Heubeck A. - West S. - Hainsworth J.B. A Commentary on Homer's Odyssey, vol. 1. Introduction and Books I-VIII, Oxford 1990.

JAeger W., Paideia, tłum. M. Plezia, Warszawa 1962.

Korus K., Mim grecki w gatunkach literackich, Prace Komisji Filologii Klasycznej PAU 47, Kraków 2015.

Latacz J., Aoiden, w: Der neue Pauly. Enzyklopädie der Antike, Stuttgart - Weimar 1996, 620-621.

Mireaux E., Życie codzienne w Grecji w epoce homeryckiej, tłum. S. Kołodziejczyk, Warszawa 1962.

Scully S.P., The Bard as the Custodian of Homeric Society: „Odyssey” 3, 263-272, „Quaderni Urbinati di Cultura Classica. New Series” 8 (1981) 67-83. 